\title{
DESAFIOS DA EDUCAÇ̃̃O INCLUSIVA NO ENSINO SUPERIOR: UM RETRATO DAS POLÍTICAS INSTITUCIONAIS DAS UNIVERSIDADES FEDERAIS DO SUL DO BRASIL
}

\author{
CHALLENGES OF INCLUSIVE EDUCATION IN HIGHER LEARNING: A PORTRAIT OF THE INSTITUTIONAL \\ POLICIES IN FEDERAL UNIVERSITIES FROM THE SOUTH OF BRAZIL
}

\author{
RETOS DE LA EDUCACIÓN INCLUSIVA EN LA EDUCACIÓN SUPERIOR: UN RETRATO DE LAS POLÍTICAS \\ INSTITUCIONALES DE LAS UNIVERSIDADES FEDERALES DE BRASIL
}

Francéli Brizolla E-mail: franbrizolla@gmail.com

Claudete da Silva Lima Martins E-mail: claudeteslm@gmail.com Universidade Federal do Pampa - UNIPAMPA \begin{abstract}
RESUMO
Este artigo apresenta os resultados de uma pesquisa-ação que teve como objetivo investigar ações institucionais realizadas por universidades federais da região Sul do Brasil, com vistas à implementação e a oferta de atendimento educacional especializado para estudantes com deficiência, transtornos globais do desenvolvimento e alta habilidades/superdotação. A pesquisa investigou a organização das políticas institucionais para implementação da educação inclusiva em nove (09) universidades federais da Região Sul, bem como a organização das ações de atendimento pedagógico para estudantes com deficiência no âmbito dessas universidades. O objeto de análise deste texto são os dados coletados por meio de questionário destinado aos núcleos de inclusão e acessibilidade de tais universidades, os quais foram respondidos pelas equipes coordenadoras dos Núcleos de Acessibilidade das universidades federais investigadas. O estudo foi desenvolvido no período de março/2014 a dezembro/2016. A partir dos dados coletados foi possível compor um "retrato" das políticas instituições vigentes em prol da educação inclusiva, evidenciando assim, os principais desafios postos às universidades.
\end{abstract}

PALAVRAS-CHAVE: Estudantes com deficiência. Educação inclusiva. Ensino Superior.

\section{ABSTRACT}

This article brings forward the results of an action research which aimed to investigate institutional actions accomplished by federal universities in the Southern Region of Brazil, in order to implement and offer specialized educational services for students with disabilities, developmental disorders and high skills/giftedness. The research investigated the organization of institutional policies for the implementation of inclusive education in nine (9) federal universities in the Southern Region of Brazil, as well as the organization of pedagogical assistance actions for students with disabilities within these universities. This article's object of analysis is the data obtained through a survey form designated to the inclusion and accessibility centers of such universities, which were answered by the coordinating teams of the Accessibility Centers in the federal universities investigated. The study was developed in the period of time from March/2014 to December/2016. Based on the data collected, it was possible to compose a "portrait" from the current institutions policies in behalf of inclusive education, therefore presenting the main challenges facing universities.

KEYWORDS: Students with disabilities. Inclusive education. Higher Education.

\section{RESUMEN}

Este artículo presenta los resultados de una investigación-acción para investigar acciones institucionales llevadas a cabo por universidades federales del sur de Brasil, con miras a la implementación y la prestación de servicio educativo especializado para estudiantes con discapacidades, trastornos del desarrollo global y alta habilidades/superdotación. La investigación investiga la organización de las políticas institucionales para la implementación de la educación inclusiva en nueve (09) universidades federales en el sur, así como la organización de servicios educativos para estudiantes con discapacidades en el contexto de estos universidades. El análisis de este objeto de texto es los datos recogidos mediante un cuestionario destinado a los corazones de la inclusión y la accesibilidad de estas universidades, que fueron respondidas por los coordinadores de los núcleos de la accesibilidad de las universidades federales investigados. El estudio se llevó a cabo durante el período de marzo a diciembre 2014/2016. De los datos recogidos fue incapaces de componer una "imagen" de las instituciones y las políticas de apoyo a la educación inclusiva, mostrando así los mensajes de los principales retos en las universidades existentes.

PALABRAS-CLAVE: Estudiantes con discapacidades. Educación inclusiva. Educación superior. 


\section{Revista Triângulo}

\section{INTRODUÇÃO}

Em tempos de implantação do sistema de cotas para alunos com deficiência no âmbito do Ensino Superior no Brasil (Lei 13.409/2016), a política de acesso e democratização está em franca discussão há, pelo menos, cinco anos, considerando o Programa INCLUIR (MEC, 2013). Tal política está em consonância com os princípios Constitucionais e com a garantia dos direitos das Pessoas com Deficiências. Isso, no entanto, não tem sido o suficiente, para assegurar a permanência desses alunos na Universidade. Os resultados evidenciam a ocorrência de dificuldades que se concentram no processo de ensino-aprendizagem e a necessidade de ações específicas, voltadas para essa parcela da população acadêmica.

Assim, a discussão quanto à Educação Inclusiva no Ensino Superior emerge em meio à diversas indagações, tais como: em qual/ais espaço/s, local/ais ou segmento/s da universidade pode/deve ocorrer esse atendimento? Quais recursos humanos (servidores) devem ser disponibilizados para o atendimento especializado dos estudantes? Qual a origem e quais recursos orçamentários são destinados para o atendimento? Estas questões encaminham a necessidade de investigações que subsidiem reflexões ao tema.

O processo de inclusão exige da universidade tomada de decisão, redefinição de paradigmas, revisão de práticas, pois estando assegurado o acesso, como promover a permanência com sucesso acadêmico? O presente artigo tem o objetivo de apresentar ações institucionais realizadas por universidades federais da região Sul do Brasil, com vistas à implementação e a oferta de atendimento educacional especializado para estudantes com deficiência, transtornos globais do desenvolvimento e alta habilidades/superdotação.

\section{DEMARCAÇÃO TEÓRICO-CONCEITUAL SOBRE A EDUCAÇÃO INCLUSIVA NA EDUCAÇÃO SUPERIOR: ORDENAMENTO LEGAL E NORMATIVO}

“Todos são iguais perante a lei, sem distinção de qualquer natureza, garantindo (...) a inviolabilidade do direito à vida, à liberdade, à igualdade, à segurança, e à propriedade" (BRASIL, 1988, Art. $5^{\circ}$ ). Com o princípio constitucional que prevê a "igualdade de condições para o acesso e permanência na escola", a sociedade brasileira passa a enfrentar o desafio da construção de sistemas educacionais inclusivos, em qualquer etapa ou modalidade; o acesso a 


\section{Revista Triângulo}

níveis mais elevados de ensino; e, atendimento educacional especializado aos portadores de deficiência, preferencialmente na rede regular de ensino (art. 206 e 208).

Como resultado da Carta Magna e da evolução relativa ao direito das pessoas com deficiência à escolarização, foi promulgada a Lei 7.853/1989, que dispõe sobre o apoio às pessoas portadoras de deficiência, sua integração social, sobre a Coordenadoria Nacional para Integração da Pessoa Portadora de Deficiência - Corde, mais tarde, com status de Secretaria Nacional de Promoção dos Direitos da Pessoa com Deficiência. No artigo $2^{\circ}$ fícou estabelecido o tratamento prioritário e adequado da oferta, obrigatória e gratuita, da Educação Especial em estabelecimento público de ensino.

$\mathrm{Na}$ década de 90, destacam-se dois movimentos significativos para a área da Educação Especial - Política Nacional de Educação Especial (1994) e Lei de Diretrizes e Bases da educação nacional (9.394/1996). A PNEE objetivou "garantir o atendimento educacional do alunado portador de necessidades especiais, cujo direito à igualdade nem sempre é respeitado". Apoiou-se na Constituição Federal (de 1988), no Estatuto da Criança e do Adolescente (de 1990), no Projeto para nova Lei de Diretrizes e Bases (de 1993) e no Plano Decenal de Educação para Todos (de 1993); destacou a importância da participação conjunta, das três esferas governamentais (federal, estadual e municipal) e da sociedade para melhoria da educação das pessoas com necessidades educacionais especiais.

A LDB 9394/96, por sua vez, ratifica os direitos conquistados e valoriza a evolução legal, estabelecendo que é dever do Estado garantir educação escolar pública com previsão de atendimento educacional especializado (AEE) gratuito aos educandos com deficiência, transtornos globais do desenvolvimento e altas habilidades e superdotação, transversal a todos os níveis, etapas e modalidades, preferencialmente na rede regular de ensino (Art. $4^{\circ}$ ).

Os anos 2000 são marcados pelo incentivo explícito à ampliação do atendimento aos estudantes com deficiência na rede regular de ensino. Um dos documentos mais importantes nesta direção foi o Plano Nacional de Educação (Lei 10.172/2001), que discute a escola inclusiva como espaço de garantia do atendimento à diversidade humana. Na esteira desta concepção, são lançadas as Diretrizes Nacionais para a Educação Especial na Educação Básica (Resolução CEB/CNE 02/03), com forte componente de incentivo à operacionalização da modalidade a partir dos pressupostos da educação inclusiva. Por sua vez, o Decreto 3.956/01 incorpora a Convenção da Guatemala na legislação brasileira e afirma os direitos humanos e as liberdades fundamentais das pessoas com deficiência, explicita que toda 
diferenciação ou exclusão da pessoa com base na deficiência é ato discriminatório e, por fim, incentiva à eliminação de toda e qualquer barreira impeditiva de acesso à escolarização.

Em 2004, novo impulso é dado ao processo de inclusão escolar através do Decreto 5296/04, popularizado como Lei da Acessibilidade, que determina prazos para a implementação da acessibilidade às pessoas com deficiência ou com mobilidade reduzida, nas diferentes áreas da acessibilidade necessárias para uma sociedade inclusiva. Tópicos específicos da educação de alguns segmentos de estudantes que apresentam necessidades educacionais especiais ganham força na discussão política, como por exemplo, a educação dos estudantes surdos, através do Decreto 5.626/05, o qual prevê a inclusão destes estudantes via Língua Brasileira de Sinais (LIBRAS) e organização da educação bilíngue no ensino comum que, dentre outros aspectos importantes, regulamenta o uso e a difusão da Libras, com previsão da inserção desta língua como componente curricular em todos os cursos de formação de professores e de fonoaudiologia, no prazo de dez anos, sendo ofertada de forma optativa para os demais cursos. Em 2007, através do Decreto 6.094/07, são estabelecidas as diretrizes do Compromisso Todos pela Educação, prevendo garantia do acesso e permanência no ensino regular e atendimento às necessidades educacionais especiais dos estudantes, fortalecendo a inclusão educacional nas escolas públicas.

A partir da conjuntura legal e normativa criada para fomentar a escolarização das pessoas com deficiência, a área da educação especial passa a atuar na especificação do atendimento educacional de acordo com o paradigma da inclusão e das políticas públicas. Assim, a Política Nacional de Educação Especial na Perspectiva da Educação Inclusiva (2008) propõe a transversalização da modalidade da educação especial, perpassando todos os níveis e modalidades de ensino da educação brasileira: a concepção que emerge é a de que a instituição educacional deve mudar para acolher todos os estudantes. Para tanto, ganha destaque a necessidade de promoção de acessibilidade - arquitetônica, urbanística, nos mobiliários e equipamentos, na informação e comunicação; da oferta de AEE (que temos compreendido como "acessibilidade pedagógica"); da participação da família e da comunidade no processo inclusivo; e da formação de professores para o AEE e dos demais profissionais para o ensino inclusivo. A concepção que emerge, então, é que a instituição educacional deve mudar para acolher todos os estudantes.

Como consequência da política de expansão da oferta de educação superior (Plano Nacional de Educação, item 4.3.1, instituído pela Lei no . 10.172/2001; Programa de Apoio à 


\section{Revista Triângulo}

Reestruturação e Expansão das Universidades Federais - REUNI, instituído pelo Decreto Presidencial $n^{\circ}$ 6.069/2007), ocorre um incentivo ao ingresso crescente de pessoas com deficiência a partir dos investimentos realizados na Educação Básica e pelo incremento da política de cotas. Nesse contexto, o momento atual para a política de educação superior exige uma reflexão a respeito da estruturação do AEE no Ensino Superior. Como questionado na Introdução se, por um lado, o acesso está assegurado, o que se diz da permanência e da efetiva participação desses sujeitos no ambiente acadêmico?

$\mathrm{Na}$ Educação Básica, o atendimento educacional especializado na perspectiva da educação inclusiva para estudantes com deficiência ainda é um tema que demanda aprofundamento teórico e diretrizes pedagógicas que garantam sua efetivação. Respeitadas as especificidades de cada nível, podemos referir que o mesmo ocorre no âmbito do Ensino Superior, sendo necessário compreensão quanto à finalidade, ao escopo, aos formatos e sujeitos (profissionais) envolvidos com esse atendimento. Assim, o AEE torna-se demanda na atual agenda políticopedagógica das instituições de Educação Superior. Porém, diversas indefinições, dúvidas e dificuldades circundam as ações de educação especial neste nível de ensino.

As políticas educacionais até agora implementadas indicam de forma genérica como tais ações devem ser subsidiadas, por exemplo, "promover o acesso, permanência e participação dos estudantes", mas não dão conta da explicitação de questões de infraestrutura e recursos humanos necessários no âmbito institucional. Aspectos pedagógicos também são fundamentais para a efetiva inclusão dos estudantes com deficiência no processo de ensino. Deste ponto, os processos de comunicação e avaliação dos estudantes com deficiência se caracterizam como elementos educacionais centrais, por exemplo.

Do ponto de vista legal e normativo para esse nível de ensino, Decreto $n^{0} 7.611 / 2011$ assim se manifesta sobre a estruturação de núcleos de acessibilidade nas instituições federais de educação superior: "Os núcleos de acessibilidade nas instituições federais de educação superior visam eliminar barreiras físicas, de comunicação e de informação que restringem a participação e o desenvolvimento acadêmico e social de estudantes com deficiência" $\left(\$ 5^{\circ}\right)$.

Por fim, o Documento Orientador do Programa INCLUIR (SECADI/SESu, 2013) propõe a construção desta política de inclusão e acessibilidade nas IFES. Criado em 2005, foi implementado até 2011 por meio de Chamadas Públicas, pelas quais as IFES apresentaram projetos de criação e consolidação dos Núcleos de Acessibilidade, visando eliminar barreiras físicas, pedagógicas, nas comunicações e informações, nos ambientes, instalações, 


\section{Revista Triângulo}

equipamentos e materiais didáticos. A partir de 2012, o MEC, por intermédio da SECADI e da SESu, passa a apoiar projetos das IFES, com aporte de recurso financeiro, diretamente, previsto na matriz orçamentária das Instituições, com a finalidade de institucionalizar ações de política de acessibilidade na educação superior, por meio dos Núcleos de Acessibilidade, nos seguintes eixos: a) infraestrutura; b) currículo, comunicação e informação; c) programas de extensão; e d) programas de pesquisa.

Como último movimento normativo-legal, destaca-se a promulgação da Lei 13.409/2016, que institui cotas para pessoas com deficiência nas universidades federais, acrescentando as pessoas com deficiência na política vigente, a qual já contempla estudantes vindos de escolas públicas, de baixa renda, negros, pardos e indígenas. Os desafios à inclusão na universidade precisam ser observados, discutidos e praticados no âmbito dos direitos humanos fundamentais, sob a ótica das ações afirmativas as quais, em nosso entendimento, do ponto de vista da diversidade, objetivam construir ambientes caracterizados pelo respeito às diferenças, cuja repercussão esperada é a inclusão social.

\section{PERCURSO TEÓRICO-METODOLÓGICO DA PESQUISA-AÇÃO}

O percurso teórico-metodológico da pesquisa-ação foi desenvolvido considerando os seguintes elementos:

2.1 Objetivos: investigar políticas institucionais realizadas por universidades federais da região Sul do Brasil, com vistas à implementação da educação inclusiva para estudantes com deficiência, transtornos globais do desenvolvimento e altas habilidades/superdotação.

Como desdobramentos operacionais, apresentaram-se os seguintes objetivos específicos:

(a) Produzir informações, a partir de coleta de dados, sobre as experiências institucionais para oferta de atendimento educacional especializado realizadas nas IFES da Região Sul;

(b) Conhecer as políticas institucionais de atendimento pedagógico a estudantes com deficiência no âmbito das IFES da Região Sul, percebendo as características daqueles designados ou intencionados como alternativas de "atendimento educacional especializado" neste nível da educação;

(c) Registrar, para análise e reflexões, as políticas institucionais de atendimento educacional para estudantes com deficiência, com levantamento das principais ações realizadas pelas universidades da Região Sul do Brasil. 


\subsection{Material e Métodos}

2.2.1 Tipo de pesquisa: baseada na metodologia da pesquisa-ação, pois esta é eminentemente participativa, interativa, democrática e dialógica, tendo como uma de suas perspectivas a possibilidade de transformação social. Assim, a pesquisa-ação proposta no próprio ambiente de trabalho dos pesquisadores possibilitará aos mesmos conhecerem, refletirem e possivelmente, atingirem níveis de transformação e melhoria das situações vivenciadas por eles quanto pelos sujeitos investigados e comunidade acadêmica em geral. $\mathrm{O}$ trabalho investigativo via pesquisa-ação tem o potencial de transcender os fundamentos teóricos, a utilização de métodos e avaliação de resultados finais, pois a compreensão do contexto e da realidade investigada passa pelos sentidos que o pesquisador atribui ao estudo e pela interação com os sujeitos da pesquisa, o critério de confiabilidade filosófica e científica de uma investigação, segundo Brandão: “(...) está bem mais no todo de seu processo de realização. E o que avalia este processo não é o rigor do método, mas a qualidade de interação entre as pessoas envolvidas na partilha de um trabalho face a face de criação de sentidos, inclusive através do uso de métodos científicos" (2003, p. 103).

Thiollent ainda define a pesquisa-ação como um tipo de pesquisa social com base empírica "que é concebida e realizada em estreita associação com uma ação ou com a resolução de um problema coletivo e no qual os pesquisadores e os participantes representativos da situação ou do problema estão envolvidos de modo cooperativo ou participativo" (1992, p. 14).

Portanto, considera-se que uma pesquisa pode ser qualificada como "pesquisa-ação quando [há] uma ação por parte das pessoas implicadas no problema sob observação" (THIOLLENT, 1992, p. 15), como se trata do caso dos sujeitos envolvidos nessa investigação, explicitados na sequência. Assim, a ação dos pesquisadores e sujeitos investigados, nesta pesquisa, está voltada para a investigação de ações institucionais que permitam delinear diretrizes para a educação inclusiva no âmbito da educação superior para estudantes com deficiência, transtornos globais do desenvolvimento e altas habilidades/superdotação.

2.2.2 Sujeitos de pesquisa: os sujeitos envolvidos nesta investigação foram os coordenadores ou servidores responsáveis pelos núcleos de inclusão e/ou acessibilidade das universidades federais da Região Sul, objeto desta investigação. Tais sujeitos foram considerados potenciais colaboradores externos à pesquisa pelo envolvimento com a gestão 


\section{Revista Triângulo}

e/ou com a operacionalização/oferta de AEE no âmbito das instituições, vinculados ou não, aos núcleos de inclusão/acessibilidade das mesmas.

2.2.3 Desenvolvimento metodológico da pesquisa e instrumentos de coleta de dados: a pesquisa foi desenvolvida em três etapas, a saber:

Quadro 1: Sistematização das etapas da pesquisa

\begin{tabular}{|c|c|c|c|}
\hline ETAPA & PERÍODO & INSTRUMENTOS & SUJEITOS \\
\hline $\begin{array}{l}1^{\text {a }} \text { etapa: análise } \\
\text { documental: } \\
\text { levantamento normativo } \\
\text { e teórico-conceitual }\end{array}$ & $\begin{array}{l}\text { Abr.-Nov. } \\
2014\end{array}$ & 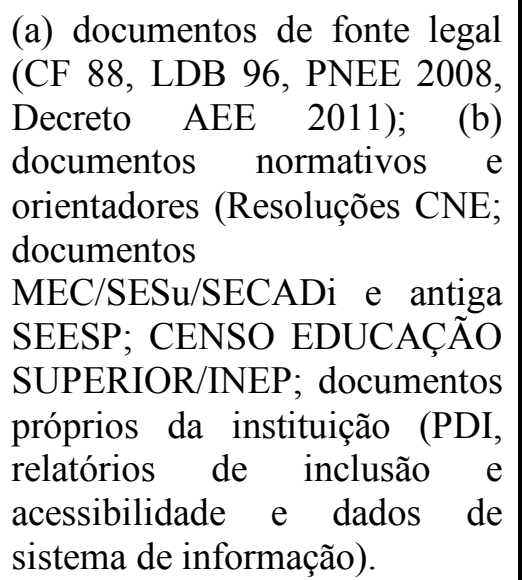 & $\begin{array}{l}\text { Equipe de Coordenação da } \\
\text { pesquisa e alunos bolsistas }\end{array}$ \\
\hline $\begin{array}{l}2^{\text {a }} \text { etapa: pesquisa } \\
\text { empírica - coleta de } \\
\text { dados Universidades } \\
\text { Federais Região Sul. }\end{array}$ & $\begin{array}{l}\text { Out./2014 } \\
- \text { Jun./2015 }\end{array}$ & $\begin{array}{l}\text { Questionário } \\
\text { dirigido às } \\
\text { Federais da Regtruturado } \\
\text { Fediversidades }\end{array}$ & $\begin{array}{l}\text { Coordenadores/membros } \\
\text { de núcleos de inclusão e } \\
\text { acessibilidade das } \\
\text { IFES/Região Sul. }\end{array}$ \\
\hline $\begin{array}{l}3^{\mathrm{a}} \text { etapa: sistematização } \\
\text { e análise de dados }\end{array}$ & $\begin{array}{l}\text { Ago./2015 } \\
- \text { Dez./2015 }\end{array}$ & $\begin{array}{l}\text { Construção de portfólio de } \\
\text { políticas de atendimento } \\
\text { educacional especializado nas } \\
\text { Universidades Federais da } \\
\text { Região Sul. } \\
\text { Elaboração de relatório. }\end{array}$ & $\begin{array}{l}\text { Equipe de Coordenação da } \\
\text { pesquisa. }\end{array}$ \\
\hline $\begin{array}{l}4^{\text {a }} \text { etapa: divulgação de } \\
\text { dados }\end{array}$ & $\begin{array}{l}\text { Jan./2016- } \\
\text { Dez./2016 }\end{array}$ & $\begin{array}{l}\text { Socialização, para validação } \\
\text { dos dados da pesquisa, em } \\
\text { evento científico. }\end{array}$ & $\begin{array}{l}\text { Equipe de Coordenação da } \\
\text { pesquisa. }\end{array}$ \\
\hline
\end{tabular}

Fonte: as autoras, 2016.

\subsection{Análise de dados da pesquisa-ação: motivações e finalidades}

A análise dos dados da pesquisa teve como base a análise de conteúdo (BARDIN, 1977), a partir do recebimento das respostas enviadas por meio do questionário de coleta de informações encaminhado aos gestores e/ou servidores responsáveis pela gestão/coordenação da política de inclusão e acessibilidade de tais Universidades. As questões solicitadas às Universidades foram construídas com foco nos determinantes legais e normativos previstos 


\section{Revista Triângulo}

em três documentos considerados essenciais à área da educação inclusiva, a saber, a Lei 9.394 (1996) e a Política Nacional de Educação Especial na Perspectiva Inclusiva (2008), as quais dispõem sobre a garantia do atendimento especializado aos estudantes com deficiências e abordam o fomento ao acesso, à participação e à aprendizagem de tais estudantes e reforçam o princípio da transversalidade da educação especial, desde a educação infantil até a educação superior. E, por fim, o Decreto 7.611 (2011), que complementa essas primeiras orientações legais, com as disposições das finalidades e operacionalização do AEE. Por ser o único dispositivo legal que aborda a implementação do serviço, a investigação buscou conhecer possíveis "traduções" de sua aplicabilidade para o desenvolvimento acadêmico dos estudantes com deficiência na Educação Superior.

A abordagem das disposições constantes do Decreto 7.611/2011 foi complementada com questões que buscaram perceber a implementação/operacionalização de outros dispositivos legais estabelecidos recentemente à avaliação institucional das Universidades, a qual é elemento obrigatório na política de Ensino Superior presente em avaliações de cursos e recredenciamento institucional, como é o caso do processo de reconhecimento dos Cursos de Graduação realizado pelo Instituto Nacional de Estudos e Pesquisas Educacionais Anísio Teixeira (INEP).

Frente a este cenário político-pedagógico, justificam-se os elementos analíticos essenciais a essa pesquisa, entendida como um processo investigativo para a área da educação inclusiva, bem como para os estudos sobre as questões da Pedagogia Universitária no âmbito da Educação Superior, principalmente quanto ao processo ensino-aprendizagem (acessibilidade pedagógica).

\section{CATEGORIZAÇÕES E ANÁLISES}

Para os propósitos do presente artigo, a análise das questões foi organizada em três categorias. A seguir serão apresentadas as categorias acompanhadas das análises construídas.

\section{Categoria 1. Contextualização do campo de pesquisa}

Quanto às Universidades convidadas à participação, o questionário foi encaminhado a onze (11) Universidades Federais da Região Sul, sendo cinco (05) destas localizadas no Rio Grande do Sul; duas (02), no Estado de Santa Catarina; e, quatro (04), no Paraná. Do total das instituições convidadas, obtivemos sete (07) respostas. Essas sete (07) respostas dizem 
respeito à participação de quatro (04) Universidades, devido à estrutura multicampi de uma dessas Universidades.

Desse modo, obtivemos uma amostra de participação disposta da seguinte forma: duas (02) Universidades situadas no Rio Grande do Sul; uma (01) situada em Santa Catarina; e duas (02) respondentes localizadas no Paraná.

Em relação à característica estrutural solicitada - multicampia - das quatro (04) Universidades participantes, três (03) contemplam estrutura multicampi, ou seja, com pelo menos uma (01) unidade a mais, além da sede.

Das Universidades envolvidas na pesquisa-ação, todas registraram resposta positiva quanto à existência de setor/núcleo de inclusão e acessibilidade já implantado. Esse é um dado bastante interessante, pois demonstra uma repercussão favorável à política proposta pelo Ministério da Educação. Destaca-se, ainda, que parte das respondentes se caracterizam como universidades federais recentemente implantadas, ao mesmo tempo em que se contou com a mesma resposta positiva de outras, com cinquenta anos, ou mais, de fundação. Os núcleos foram implantados entre os anos de 2008 a 2014 e, sem exceção, todos estão vinculados à política da graduação, seja no Gabinete ou em algum outro setor da referida pró-reitoria (diretorias específicas). Em uma das instituições multicampi, são registrados setores de acessibilidade nas unidades acadêmicas, sugerindo uma política descentralizada e/ou em rede.

Quanto aos profissionais que atuam nos núcleos de inclusão e acessibilidade, predominam equipes compostas por: técnicos em assuntos educacionais e/ou pedagogos (em algumas Universidades, existe um ou outro desses profissionais) e intérprete de LIBRAS. Esses dois servidores são mencionados na totalidade das respondentes. Em duas (02) das quatro (04) instituições, é citada a existência de psicólogo. Em uma (01), além dos profissionais já arrolados, menciona-se a presença de assistente em administração. E, em apenas uma das respondentes, há uma equipe bastante ampliada de intérprete de LIBRAS - nove (09) profissionais, índice muito acima da média de, no máximo, um (01) a dois (02), nas demais instituições. Não foram mencionadas equipes de apoio ou voluntariado.

Numa análise geral, pode-se depreender que os núcleos ainda estão em fase de demanda e conquista de vagas específicas para o setor, em franca consolidação de equipes na maioria das Universidades participantes. 


\section{Revista Triângulo}

\section{Categoria 2. Identificação, registro e acompanhamento}

Nessa categoria, procurou-se observar três critérios considerados fundamentais para a efetivação do acesso e posterior permanência do estudante ingressante com deficiência na Universidade. Assim, observaram-se questões quanto à identificação, ao registro e ao acompanhamento, conforme segue.

No que diz respeito à identificação (comprovação), para a instituição, da deficiência declarada pelo estudante, apresenta-se uma variedade de procedimentos utilizados, tendo sido indicados os três elementos disponibilizados como possibilidade de resposta à questão: autorrelato do aluno/família - uma (01) instituição e um (01) campus, apenas, de uma instituição multicampi; exclusivamente por atestado médico - citado por duas (02) Universidades respondentes; e análise do servidor responsável pelo cadastro/matrícula do aluno, opção de escolha de uma (01) Universidade. Destaca-se que apenas uma (01) das Universidades respondentes, dentre as quatro (04) participantes, mencionou a triangulação dos elementos sugeridos pela pesquisa, como prática de identificação e comprovação da condição de deficiência.

Quanto ao fluxo de cadastro e matrícula dos referidos estudantes, todas as participantes mencionaram que essa tarefa é uma atribuição da Secretaria Acadêmica da Universidade e dos campi. Nesses setores, os servidores responsáveis pela atividade são técnicos administrativos sem capacitação em AEE ou outra formação específica na área.

Finalmente, quanto à realização de encaminhamento do aluno com deficiência ingressante para algum núcleo/setor de atendimento educacional especializado da Universidade, procurou-se observar três situações: inexistência de encaminhamento, existência de encaminhamento ou encaminhamento mediante demanda do estudante. A totalidade das instituições participantes respondeu que, a partir da identificação/registro, realiza encaminhamento ao setor/núcleo que disponibiliza algum tipo de atendimento especializado.

O "acompanhamento" foi caracterizado pela maioria das Universidades participantes como providências gerais/pontuais de: (a) acolhimento dos estudantes pelos núcleos; (b) verificação de demandas pedagógicas/necessidades individuais; (c) providências de recursos materiais e serviços (empréstimo de notebooks com programas leitores de tela e gravadores; adaptação de material pedagógico; equipamento de tecnologia assistiva; digitalização de material, etc.) e humanos (tradução e interpretação em LIBRAS; mediação/apoio de estudantes tutores). Uma das participantes mencionou abertura de processos pedagógicos após 


\section{Revista Triângulo}

registro acadêmico. A participante com maior número de campus relata contato para orientação de coordenadores de cursos e formação docente, embora essas ações não sejam padrão para todos os campi da referida Universidade. Relata, ainda, acompanhamento psicológico e de assistência social em um de seus campi. Formação continuada, orientação docente e verificação das condições de acessibilidade também são relatadas, porém, sem maiores detalhamentos, o que pode indicar a ausência de um planejamento sistemático dessas ações por parte das Universidades que referiram tais atividades.

Em relação ao acompanhamento/monitoramento pedagógico dos estudantes, por sua vez, as participantes também foram unânimes ao indicar que realizam esse tipo de ação, que pode ser caracterizada da seguinte forma: - a organização do acompanhamento pedagógico é realizada, preferencialmente, pelo pedagogo e, em segundo lugar, pelo técnico em assuntos educacionais do núcleo; - quando é o caso, tem-se um trabalho interdisciplinar/multiprofissional nesse atendimento com participação de psicólogo, tradutor e intérprete de LIBRAS, assistente social, componentes exclusivos do núcleo (fato mencionado por apenas uma Universidade); - em apenas duas participantes se observa a menção a equipes multiprofissionais com trabalho colaborativo/parceria institucional externa ao núcleo (próreitoria de assuntos estudantis e ou outro setor vinculado à Reitoria); - predominam acompanhamentos realizados sob demanda estudantil; - não foi expressiva a menção às associações/entidades externas à Universidade para o acompanhamento pedagógico, embora uma participante tenha indicado essa situação.

Nesse quesito, é possível afirmar que as Universidades estão compromissadas com a regularidade dos processos acadêmico-administrativos dos estudantes com deficiência, numa etapa em que além de propiciar e reconhecer o direito ao acesso, já se busca efetivar o encaminhamento institucional adequado, o que pode ser um fator positivo para a vinculação do estudante e de um desenvolvimento acadêmico satisfatório. Dados apontam que o maior índice de evasão/abandono de estudos no nível universitário ocorre no primeiro ano de estudos. Por essa razão, essa é uma categoria de fundamental importância na análise do percurso educacional dos estudantes, com e sem deficiência, pois apresenta implicações que repercutirão, positiva ou negativamente, ao longo da formação. Por outro lado, quando se entende que a ação do núcleo de acessibilidade seria de ordem macro institucional, é possível identificar fragilidades nesse quesito, estando o critério "acompanhamento", portanto, muito mais relacionado a demandas individuais do que providências institucionais e coletivas, em 


\section{Revista Triângulo}

parte, possivelmente, pelas incipientes e jovens estruturas das Universidades que fizeram menção a esses quesitos sem especificá-los, em parte, talvez, pela insuficiência de composição de equipes de trabalho ou, ainda, pela ausência de regimentação institucional e decorrentes providências para a plena realização do atendimento especializado. É possível identificar uma "solidão pedagógica" dos núcleos e uma insuficiente relação do trabalho dos mesmos com as políticas estudantis (de graduação e assuntos estudantis, por exemplo) mais amplas.

Categoria 3. Ações de desenvolvimento acadêmico: âmbitos do Ensino, da Pesquisa e da Extensão

Nesse grupo de questões, a pesquisa buscou informações quanto à tríade ensino-pesquisaextensão, entendendo a necessidade de ocorrência do previsto no Programa INCLUIR (BRASIL, 2013) e no Decreto 7.611 (BRASIL, 2011), que tratam da transversalidade. Assim, no âmbito das disciplinas/componentes curriculares, o foco foi investigar a presença de formas de adaptação/flexibilização nas atividades de ensino. Das quatro (04) Universidades, três (03) referiram à existência da flexibilização. No que tange à existência de mecanismos institucionais de estímulo à participação de estudantes com deficiência em atividades de extensão, todas as Universidades participantes responderam negativamente. E, quanto às políticas de participação dos estudantes com deficiência na pesquisa, duas (02) participantes mencionaram atividades que tangenciam pesquisa com instituições externas, sendo que isso ocorre em apenas um campus de uma das Universidades multicampi, e duas (02) responderam que não há estímulo/fomento para a participação dos estudantes com deficiência nessa área.

Para encerrar, ainda foram solicitadas duas questões específicas: adaptação regulamentada/regimentada para o processo de avaliação para os estudantes com deficiência e oferta, pela instituição, de atividades de capacitação/formação sobre a educação inclusiva e acessibilidade para servidores. Quanto à avaliação, das quatro (04) participantes, apenas uma (01) não realiza e não prevê adaptação na avaliação, tampouco, regulamentação. Nas demais, são consideradas adaptações na avaliação os seguintes elementos: - adaptação de material/digitalização de materiais e de trabalhos e provas; - tempo extra; - empréstimo de notebook para leitura em áudio; e - realização de atividades de avaliação fora da sala de aula. Importante frisar que duas (02) das três (03) Universidades que responderam positivamente não elencaram de forma objetiva as adaptações e/ou flexibilizações realizadas, mencionando apenas que as adaptações são verificadas junto aos cursos. 


\section{Revista Triângulo}

A princípio, pode-se depreender que, embora existam registros e atividades diferenciadas, ocorre: (a) uma redução da compreensão do processo avaliativo - que é muito mais amplo que verificação; (b) uma confusão com respeito aos elementos da organização do trabalho pedagógico - entre metodologia, recursos e processo de verificação da aprendizagem; e (c) que não existe, ainda, uma normatização específica para essa questão nas Universidades investigadas.

\section{CONSIDERAÇÕES FINAIS}

A partir da análise de dados realizada, percebeu-se que as políticas institucionais desenvolvidas pelas Universidades Federais da região Sul do Brasil, com vistas à implementação da educação inclusiva para estudantes com deficiência, transtornos globais do desenvolvimento e alta habilidades/superdotação são preponderantemente vinculadas, ainda, à efetivação da garantia do acesso desses estudantes à Educação Superior, com limitada inserção no processo geral do desenvolvimento acadêmico. Portanto, são muitos os desafios enfrentados pelas universidades, considerando que há uma evidente fragilidade de incorporação de políticas institucionais voltadas à inclusão dos alunos com deficiência na política geral das instituições, o que se reflete na estrutura mínima dos núcleos, seja em ambiente/espaço de trabalho; na composição das equipes multidisciplinares; e, por fim, nas limitações de atendimento à tríade ensino-pesquisa-extensão, no que diz respeito à garantia de inclusão dos estudantes com deficiência.

Sendo assim, mesmo tendo ciência da necessidade de aprofundamento dos dados obtidos, o "retrato" da educação inclusiva nas instituições de Ensino Superior investigadas, revela uma tendência de implementação de políticas institucionais como provimento de "serviços e recursos pontuais" por demandas/necessidades individuais dos estudantes com deficiência. Questiona-se quanto às implicações dessa interpretação, pois parece deslocar a discussão da inclusão como fenômeno macro no processo educacional, sem tangenciar questões que, a nosso ver, extrapolam a simples implementação de técnicas e recursos, como já outrora se caracterizou a Educação Especial. Há uma tendência da vinculação da concepção de educação inclusiva na Educação Superior como mera disponibilização de recursos de tecnologia assistiva, produção de material acessível e apoio ao professor quanto ao planejamento, porém, sem integração progressiva à concepção de "acesso universal". Compreendemos que a 
educação inclusiva não se reduziria a isso: deve contribuir para as transformações na universidade que pretende acolher as diferenças.

Tratar da inclusão educacional, institucional e universitária de estudantes com deficiência parece ser mais; é questionar o "pano de fundo" da discussão político-pedagógica na universidade, assim como se fez no âmbito das escolas básicas.

\section{REFERÊNCIAS}

BARDIN, L. Análise de conteúdo. Lisboa: Edições 70, 1977.

BRANDÃO, Carlos Rodrigues. A pergunta a várias mãos: a experiência da partilha através da pesquisa na educação. São Paulo: Cortez, 2003. (Série saber com o outro; v. 1).

BRASIL. Constituição (1988). Brasília, DF: Senado Federal, 1988.

. Decreto n. 6960, de 24 de abril de 2007. Institui o Programa de Apoio a Planos de Reestruturação e Expansão das Universidades Federais. Brasília, 2007.

Plano Nacional de Educação - Lei n. 10.172, de 09 de janeiro de 2001. Brasília, 2001.

Decreto n. 5.296 de 02 de dezembro de 2004. Regulamenta as Leis nos 10.048 , de 8 de novembro de 2000, que dá prioridade de atendimento às pessoas que especifica, e 10.098, de 19 de dezembro de 2000, que estabelece normas gerais e critérios básicos para a promoção da acessibilidade das pessoas portadoras de deficiência ou com mobilidade reduzida, e dá outras providências. Brasília, DF: Presidência da República/Casa Civil, 2004.

Decreto n. 5.626 de 22 de dezembro de 2005. Regulamenta a Lei $n^{\circ} 10.436$, de 24 de abril de 2002, que dispõe sobre a Língua Brasileira de Sinais - Libras, e o art. 18 da Lei ${ }^{\circ}$ 10.098, de 19 de dezembro de 2000. Brasília, DF: Presidência da República/Casa Civil, 2005.

Decreto n. 6.949, de 25 de agosto de 2009. Promulga a Convenção Internacional sobre os Direitos das Pessoas com Deficiência - ONU. Brasília, DF: Diário Oficial da União, 2009.

. Decreto n. 7.611 de 17 de novembro de 2011. Dispõe sobre a educação especial, o atendimento educacional especializado e dá outras providências. Brasília, DF: Senado Federal, 2011.

Lei n. 7.853 de 24 de outubro de 1989. Dispõe sobre o apoio às pessoas portadoras de deficiência. Brasília, DF: Presidência da República/Casa Civil, 1989.

Lei n. 9.394 de 20 de dezembro de 1996. Estabelece as diretrizes e Bases da Educação Nacional. Brasília, DF: Presidência da República/Casa Civil, 1996.

Portaria Ministerial n. 3284 de 7 de novembro de 2003. Dispõe sobre requisitos de acessibilidade de pessoas portadoras de deficiências, para instruir os processos de autorização e de reconhecimento de cursos, e de credenciamento de instituições. Brasília, DF: Ministério da Educação, 2003.

PROGRAMA INCLUIR. Documento orientador: acessibilidade na educação superior. Brasília, DF: SECADI/SESu, 2013.

THIOLlENT, M. J. M. Metodologia da pesquisa-ação. São Paulo: Cortez/Autores Associados, 1992. 